\title{
GELIAT WIRAUSAHA MUDA DALAM MELESTARIKAN KOPI LOKAL BALI
}

\author{
Ni Luh Made Vinaya Medhiatika \\ Jurusan Manajemen, Fakultas Ekonomi dan Bisnis Universitas Sahid \\ Jl.Prof. Dr. Soepomo No.84, Tebet, Jakarta Selatan \\ Email Korespondensi: madevinaya@gmail.com
}

\begin{abstract}
ABSTRAK
Indonesia memiliki beragam tradisi, termasuk tradisi minum kopi. Tradisi minum kopi ini menggerakkan para wirausaha, terutama wirausaha muda untuk merintis usaha kedai kopi. Geliat ini juga terjadi di pulau Bali, salah satunya adalah kedai kopi Bhineka Muda. Tujuan penelitian ini ingin menunjukkan bahwa wirausaha muda memiliki semangat yang luar biasa dalam melestarikan kopi asli Bali yang sudah ada sejak tahun 1935 sehingga tidak kalah dengan kopi merek Internasional. Peneliti melakukan wawancara mendalam dengan Pak Putu Gde Ary Wicahyana, penggerak revitalisasi kedai kopi Bhineka Djaja dan dibukanya kedai Bhineka Muda. Metode penelitian kualitatif ini dilakukan dengan wawancara yang mengalir dengan pertanyaan tidak terstruktur mulai dari merek kopi, konsep kedai kopi, hingga sociopreneur. Berdasarkan hasil wawancara menunjukkan bahwa dalam memulai suatu usaha dibutuhkan inovasi dan kreatifitas layaknya konsep ekonomi kreatif yang kemudian ditumpahkan pada kedua kedai kopi tersebut, berbeda konsep namun dengan tujuan sama untuk melestarikan kopi Bali. Penelitian ini juga menunjukkan bahwa Pak Ary terbukti memiliki ciri atau karakter dari seorang wirausahawan yang sukses. Beliau juga menantang dirinya untuk menjadi seorang wirausaha muda ekonomi kreatif berbasis budaya serta menjadi sociopreneur. Peneliti menyimpulkan bahwa wirausaha yang hebat tidak hanya memikirkan laba tetapi bisa menjadi sociopreneur atau wirausaha yang juga memberi dampak yang positif, terutama di bidang sosial dan lingkungan bagi para pemangku kepentingan di lingkungan usahanya.
\end{abstract}

Kata Kunci: wirausaha, sociopreneur, kopi, Bali

\begin{abstract}
Indonesia has many traditions, one of them is sipping coffee. This tradition, drives young entrepreneurs to start their business with open a coffee stall, serving Indonesian traditional coffee. Opened a coffee stall also happens in Bali, one of them is Bhineka Muda coffee stall. Aim of this research is to indicate that this young entrepreneur has a great spirit to reserve one of Bali local brand coffee that already established since 1935 to fight against International brand coffee. Researcher choose to held in depth interview with Mr. Ary, the mastermind behind the revitalization of Bhineka Djaja coffee stall and the new concept of Bhineka Muda stall. Method of this research was a qualitative method with the unstructured interview that flown from branding of the coffee, concept of the stall, up to sociopreneur. Results from interview indicated that as a young entrepreneur, he/she needs continuous innovation and creativity, as presented in two coffee stalls, different concepts but still in one goal, to reserve Bali local coffee. On this research also revealed Mr. Ary's his character and spirit as a successful young entrepreneur. He also challenges himself not only become a successful entrepreneur but also become a sociopreneur or an entrepreneur that cares about social and environment around his coffee business.
\end{abstract}

Keywords: entrepreneur, sociopreneur, coffee, Bali 


\section{PENDAHULUAN}

Indonesia merupakan negara produsen utama kopi dunia dengan varian produk yang beragam dan kualitasnya diakui di pasar Internasional. Dibalik ketimpangan antara pertumbuhan konsumsi kopi nasional dengan tingkat produksi, Indonesia sudah memiliki 21 jenis kopi yang dikategorikan sebagai coffee specialty dan memiliki sertifikasi Indikasi Geografi dari Kementrian Hukum dan HAM sebagai produk berkualitas dan spesifik. Kualitas kopi yang baik didukung oleh kebiasaan masyarakat Indonesia untuk minum kopi bahkan sudah menjadi tradisi di beberapa daerah seperti Sumatera, Jawa, dan Bali. Penikmat kopi menikmati kopi tanpa ada batasan waktu, bisa dari pagi hingga malam hari sehingga kedai kopi pun mudah ditemukan dimana-mana.

Gaya hidup minum kopi di kedai kopi menjadi peluang bagi pengusaha, terutama pengusaha muda untuk membuka usaha dan juga untuk melestarikan produksi kopi lokal daerahnya. Bhineka Muda merupakan salah satu dari sekian banyak kedai kopi di Bali, tepatnya di kota Denpasar. Perbedaan kedai ini dibandingkan kedai kopi lain adalah kedai ini hanya menjual kopi dengan merek dagang Kopi Bali cap Kupu-kupu Bola Dunia yang sudah ada sejak tahun 1935. Bhineka Muda lahir dari pemikiran seorang seniman Bali, Pak Putu Gde Ary Wichayana, yang sangat peduli dengan keberadaan kopi asli Bali ini. Beliau khawatir, kopi asli Bali akan ditinggalkan (terutama oleh kaum muda) karena munculnya kopi dengan merek global yang ada di pasar modern. Sebelum membuka kedai Bhineka Muda, beliau juga merevitalisasi toko kopi Bhineka Djaya di kawasan bersejarah Denpasar menjadi kedai kopi yang menarik bagi siapapun yang melewati Jalan Gajah Mada tersebut. Untuk menarik konsumen, terutama usia muda atau milenial, Pak Ary melakukan inovasi pada varian penyajian kopi, tidak hanya kopi seduh tapi juga menyajikan affogato atau kopi yang disiramkan pada es krim untuk menghasilkan cita rasa yang luar biasa berbeda. Kedai kopi yang kedua, Bhineka Muda terbuka untuk siapapun yang ingin menikmati kopi dan aneka makanan pendamping dengan anggaran tidak lebih dari 50.000 rupiah. Kedai dengan tagline "Yes, I am Bhineka" tidak hanya menjajakan minuman kopi tetapi juga menjual aneka jajanan dengan mengajak kerjasama konsumen yang memiliki usaha kue/kudapan tradisional.

Pemilik kedai tidak hanya mementingkan keuntungan namun juga berupaya untuk meningkatkan ekonomi kreatif dan ekonomi yang saling berbagi atau sharing economy. Satu hal yang bisa dipastikan bahwa minum kopi bisa membuat semua orang bahagia. Penelitian ini ingin menunjukkan bagaimana besarnya jiwa pengusaha muda Bali untuk melestarikan tradisi dan produki kopi lokal Bali, meningkatkan ekonomi kreatif, serta menularkan jiwa wirausaha bagi siapa pun yang memiliki visi yang sama.

Saat ini, inovasi atas sesuatu yang sudah ada sebelumnya masuk dalam kategori Ekonomi Kreatif dimana menurut Howkins (2012) dalam El Hasanah (2015) didefinisikan sebagai ekonomi yang menjadikan kreatifitas, budaya, warisan budaya dan lingkungan sebagai tumpuan masa depan. Ekonomi kreatif berbasis budaya lokal menurut Zulbetti (2015) dalam El Hasanah (2015) adalah ekonomi yang mengandalkan kreatifitas masyarakat dengan memanfaatkan potensi budaya lokal yang tersedia untuk dimanfaatkan sebagai modal dalam memperoleh keuntungan. Seorang wirausahawan (entrepreneur) menurut Zimmerer dan Scarborough (2008) adalah seseorang yang menciptakan bisnis baru dengan mengambil resiko dan ketidakpastian demi mencapai keuntungan dan pertumbuhan dengan cara mengidentifikasi peluang yang signifikan dan menggabungkan sumber-sumber daya yang diperlukan sehingga sumber-sumber daya itu bisa dikapitalisasikan. 
Profil wirausahawan dalam Zimmerer dan Scarborough (2008); (1) hasrat akan tanggungjawab, (2) lebih menyukai resiko menengah, (3) meyakini kemampuannya untuk sukses, (4) hasrat untuk mendapatkan umpan balik yang sifatnya segera, (5) tingkat energi yang tinggi, (6) orientasi masa depan, (7) ketrampilan mengorganisasi, dan (8) menilai prestasi lebih tinggi daripada uang.

Adapun ciri-ciri utama yang ada di dalam diri seorang entrepreneur yang telah sukses; (1) mempunyai mimpi-mimpi yang realistis dan tinggi, yang mampu diubah menjadi cita-cita yang harus dicapai. Hidupnya ingin berubah karena kekuatan emosionalnya yang tinggi dan keyakinannya yang kuat sehingga mimpi itu bisa terwujud (power of dream), (2) mempunyai karakter dasar kekuatan emosional yang saling mendukung untuk sukses yaitu: determinasi, persistence, keberanian, struggle, dan risk manager, (3) menyukai tantangan dan tidak pernah puas dengan apa yang didapat (high achiever), (4) mempunyai ambisi dan motivasi yang kuat (motivator), (5) memiliki keyakinan yang kuat akan kemampuannya bahwa "dia bisa" (power of mind), (6) seorang visioner dan mempunyai daya kreativitas yang tinggi, (7) risk manager not just risk taker, (8) memiliki kekuatan emosional (strong emotional attachment), (9) seorang problem solver, (10) mampu menjual dan memasarkan produknya (seller), (11) mudah bosan dan terkesan orang yang sulit diatur, dan (12) seorang creator ulung. Definisi entrepreneur menurut Drucker dalam Dash dan Kaur (2012) "entrepreneur as one who always searches for change, respond to it and exploit it as an opportunity" yang artinya wirausaha adalah seseorang yang selalu mencari perubahan, merespon dan mengeksploitasi perubahan tersebut menjadi sebuah peluang. Definisi lain dari Schumpeter seperti dikutip dalam Dash dan Kaur (2012) "an entrepreneur is a person who is willing and able to convert a new idea or invention into a successful innovation".

Seorang wirausaha adalah seseorang yang mau dan mampu untuk mengubah suatu ide atau penemuan menjadi inovasi yang berhasil. Sikap seorang wirausahawan menurut Hendro (2011) adalah: (1) sikap selalu berpikir positif dalam menghadapi segala hal (positive thingking), (2) respons positif dari individu terhadap informasi, kejadian, kritikan, cercaan, tekanan, tantangan, cobaan, dan kesulitan, (3) sikap berorientasi jauh ke depan, berpikiran maju, bersifat prestatif dan tidak mudah terlena oleh hal-hal yang sudah berlalu (think for future, not the past), tidak mau hanyut oleh hal-hal yang bersifat sejarah dan kenyamanan sesaat, (4) sikap tidak gentar saat melihat pesaing (competitor), (5) sikap yang selalu ingin tahu, membuat ia selalu mencari jalan keluar bila ingin maju, (6) sikap yang ingin memberi yang terbaik buat orang lain sehingga sikap ini sangat baik untuk semua orang, (7) sikap yang penuh semangat dan berjuang keras (pantang menyerah) sehingga menimbulkan dampak yang baik untuk dunia sekelilingnya, dan (8) punya komitmen yang kuat, integritas tinggi, dan semangat yang kuat untuk meraih mimpinya. Pengembangan kewirausahaan lebih banyak ditujukan kepada pengusaha untuk memiliki karakter-karakter unggul dalam meningkatkan kualitas hidupnya melalui perusahaan yang dijalankannya.

Pengembangan aspek perusahaan banyak ditujukan untuk memperbaiki dan mengembangkan manajerial perusahaan termasuk fungsi produksi, keuangan, pemasaran, serta fungsi manajemen dan organisasi. Indonesia merupakan negara yang besar. Bonus demografi dengan jumlah penduduk usia produktif yang besar menjadikan Indonesia potensial untuk melahirkan aktor-aktor ekonomi muda yang dikenal sebagai pebisnis sosial (sociopreneur). Wirausahawan sosial (social entrepreneurs) menurut Zimmerer dan Scarborough (2008) adalah wirausahawan yang menggunakan berbagai keahlian mereka tidak hanya untuk membuat bisnis menjadi menguntungkan, tetapi juga untuk mencapai tujuan sosial dan lingkungan bagi kebaikan bersama. 
Kewirausahaan sosial menjadi salah satu bentuk perubahan baik karena konsep yang diangkat adalah membangun bisnis untuk mengatasi masalah sosial, ekonomi, dan lingkungan (Suyatna dan Nurhasanah, 2017). Kewirausahaan sosial dimaknai sebagai aktivitas inovatif yang menciptakan nilai sosial di dalam atau melalui sektor pemerintah, bisnis, atau nirlaba seperti yang disampaikan oleh Austin, Stevenson, dkk (2006) dalam Suyatna dan Nurhasanah (2017). Global Entrepreneurship Index (GEI) seperti yang dikutip Suyatna dan Nurhasanah (2017) menetapkan 13 indikator untuk melihat apakah sebuah negara dapat membangun ekosistem entrepreneurship dengan baik. Indikator GEI tersebut terdiri dari: (1) pandangan terhadap peluang (2) ketrampilan start-up (3) penerimaan resiko (4) jaringan (5) dukungan budaya (6) penyerapan teknologi (7) sumber daya manusia (8) kompetisi (9) inovasi produk (10) proses inovasi (11) pertumbuhan tinggi (12) internasionalisasi dan (13) modal resiko. Kusumasari (2015) dalam Suyatna dan Nurhasanah (2017) menitikberatkan 3 aspek untuk menganalisis desain suatu bisnis, yaitu; (1) value proposition (preposisi nilai), (2) value creation (penciptaan nilai), dan (3) value capture (tangkapan nilai).

Value proposition atau preposisi nilai dilihat dari latar belakang pembentukan organisasi, tujuan yang ingin dicapai bisnis, isu sosial yang ingin dijawab, siapa yang menjadi pelanggannya, dan apa yang ditawarkan kepada pelanggan atau pengguna jasa/produk bisnis. Selain preposisi nilai, value creation atau penciptaan nilai mencakup aktivitas bisnis untuk mencapai nilai bisnis, cara kerja, keberlanjutan suatu perusahaan dengan siapa perusahaan melakukan kerjasama, dan pembiayaan aktivitas suatu akhir. Pada akhirnya, value capture atau tangkapan nilai menekankan pada cara bisnis mendapatkan keuntungan, definisi sukses bagi suatu bisnis, dan pengukuran kinerja sociopreneur atau dalam pencapaian kinerja. Seorang sociopreneur mengembangkan bisnis sosialnya selain untuk menambah nilai dari produk sebelumnya (hanya sebatas bahan dasar) menjadi produk yang lebih bernilai guna. Sociopreneur pada hakikatnya wajib memiliki kapasitas dalam mentransfer nilai-nilai baik dalam berwirausaha kepada masyarakat mitra binaannya. Nilai yang ditransfer adalah nilai-nilai kepercayaan yang dihimpun oleh sociopreneur agar dapat menarik minat kepercayaan untuk mau bekerja sama dengan sociopreneur tersebut.

Banyaknya kedai kopi yang bermunculan belakangan ini menjadikan pada pengusaha tidak bisa menghindar dari persaingan. Wirausahawan juga harus memikirkan persaingan salah satunya melalui pemasaran yang tepat. Seorang wirausahawan harus mempelajari faktor-faktor utama perilaku konsumen seperti yang dikutip dalam Hendro (2011) yaitu; (1) faktor budaya, (2) kelas sosial, (3) keluarga, (4) usia dan tahap siklus hidup, (5) jenis pekerjaan, (6) kondisi ekonomi, dan (7) gaya hidup. Untuk pemasaran, saat ini pemasaran yang tepat adalah dengan pemasaran hubungan (relationship marketing) atau manajemen hubungan pelanggan (customer relationship management/ CRM) yang merupakan suatu proses pengembangan, pemeliharaan, dan pengelolaan hubungan jangka panjang dengan pelanggan sehingga mereka tetap kembali berbelanja (Zimmerer dan Scarborough, 2008).

Wirausahawan dapat mencapai keempat tingkat keterlibatan pelanggan seperti berikut ini; (1) tingkat 1 yaitu customer awareness atau kesadaran pelanggan, lalu (2) tingkat 2 yaitu customer sensitivity atau kepekaan pelanggan, kemudian (3) tingkat 3 yaitu customer alignment atau kesejajaran dengan pelanggan, dan tingkat tertinggi (4) tingkat 4 dimana terjadi customer partnership atau kemitraan dengan pelanggan. Persaingan tidak cukup hanya dari aspek pemasaran. Hendro (2011) mengatakan bahwa ada 6 faktor penting yang mempengaruhi laju pergerakan dan pertumbuhan usaha sepert: (1) menjaga kualitas adalah kunci utama untuk bertahan (survive), (2) fokus sebagai salah satu kunci sukses menjalankan bisnis, (3) mengibarkan popularitas merek dengan reputasi karena 
kualitas, (4) membangun keunggulan proses dan operasional yang prima dengan sistem manajemen kualitas yang baik, (5) memotivasi sumber daya manusia, dan (6) manuver dan taktik bisnis untuk keluar dari krisis selama menjalankan usaha.

\section{METODE PENELITIAN}

Objek penelitian ini adalah seorang wirausaha muda penggagas serta pemilik kedai kopi Bhineka Muda di Jl. Merdeka, Denpasar, Bali. Metode yang dipilih pada penelitian kewirausahaan ini adalah metode kualitatif, yaitu metode yang memadukan analisis data dengan aspek-aspek yang terkait. Jenis data berupa data primer didapat langsung peneliti dari sumbernya yaitu Pak Putu Gde Ary Wicahyana, pengusaha pemilik kedai. Metode pengumpulan data dengan melakukan depth interview atau wawancara mendalam secara langsung. Wawancara dilakukan di kedai kopi Bhineka Muda pada pertengahan bulan Desember 2018. Peneliti membuat panduan wawancara dengan pertanyaan-pertanyaan seputar ide/gagasan usaha serta bagaimana menjalankan usahanya. Pertanyaan berdasarkan pada teori tentang kewirausahaan, ekonomi kreatif, dan sociopreneur. Hasil wawancara akan dianalisis kembali berdasarkan teori dan penelitian-penelitian sebelumnya.

\section{HASIL DAN PEMBAHASAN}

Melestarikan budaya Bali sudah menjadi kewajiban bagi setiap generasi muda. Seorang Putu Gde Ary Wicahyana, komikus "The Cronicle of Calonarang and Baladeva" ini tergerak untuk melestarikan budaya Bali lewat kuliner yaitu kopi Bali. Hal ini sejalan dengan gambaran kategori ekonomi kreatif menurut Howkins (2012) dalam Hasanah (2015), dimaksudkan sebagai ekonomi yang menjadikan kreatifitas, budaya, warisan budaya dan lingkungan sebagai tumpuan masa depan. Ekonomi kreatif berbasis budaya lokal menurut Zulbetti (2015) dalam Hasanah (2015) adalah ekonomi yang mengandalkan kreatifitas masyarakat dengan memanfaatkan potensi budaya lokal yang tersedia untuk dimanfaatkan sebagai modal dalam memperoleh keuntungan. Kedua hal diatas secara nyata dilakukan oleh Pak Ary.

Kecintaannya pada budaya dan sejarah dibuktikan dengan bergabungnya beliau dalam program Pemerintah “Denpasar's Smart City Committee” yang memang salah satu agendanya adalah melestarikan bangunan tua di kota Denpasar. Berawal dari obrolan warung kopi dengan Pak Wie, pemilik asli kedai kopi Bhineka Djaja, Pak Ary diminta untuk mengubah konsep kedai kopi yang hanya menyediakan kopi sembari menunggu kopi yang dibeli untuk digiling, menjadi kedai kopi yang lebih menarik. Jika awalnya peneliti mengira Pak Ary adalah putra dari Pak Wie ternyata salah. Jiwa wirausaha tidak selalu diturunkan dari orangtua ke anaknya, namun bisa muncul dari kecintaan terhadap sesuatu. Kecintaan disini adalah kecintaan pada kopi Bali yang asli atau original sehingga tidak tergerus oleh kopi modern. Pak Ary merupakan mastermind untuk berubahnya kedai Bhineka Djaja dan berdirinya Bhineka Muda. Supply kopi untuk produk minuman yang dijual di Bhineka Muda semua berasal dari Bhineka Djaja.

Kopi yang digunakan adalah jenis Bali Gold yang merupakan salah satu varian terbaik dari produk Kopi Bali cap Kupu-kupu Bola Dunia. Inovasi sudah menjadi langkah pertama, inovasi di variasi minuman yang aslinya hanya kopi seduh kemudian dikembangkan menjadi latte, cappuccino, hingga affogato. 
Bhineka Muda didirikan dengan konsep warung kopi dimana dengan uang 50.000 rupiah, konsumen bisa menikmati kopi diselingi kudapan ringan atau bahkan sebungkus nasi Bali. Jika menilik sekilas tentang kosa kata bhineka yang berarti berbeda-beda, maka kedai kopi ini menerima konsumen dengan latar belakang yang berbeda, tanpa pandang bulu. Kedai inipun menjunjung slogan "I am Bhineka". Interior pada kedai ini berupa lukisan Soekarno dengan pemimpin Cina, lukisan aneka wajah rakyat, dan juga Garuda Pancasila.

Pemilik menerangkan bahwa siapapun pemimpinnya, rakyat bisa minum kopi dengan tenang dan bahagia. Burung Garuda Pancasila menjadi lambang pemersatu, dimana slogan Bhineka Tunggal Ika memang terdapat pada kaki burung tersebut. Nuansa heritage sangat terasa di kedai ini. Human interest juga menjadi konsep kedai kopi ini dimana suasana kebersamaan, storytelling, dan tidak tersedianya wi-fi membawa nuansa asli warung kopi jaman dulu; duduk - minum kopi- dan saling berkomunikasi tatap muka tanpa gawai/gadget. Kedai ini juga didesain menjadi creative hub dimana konsumen bisa bertukar pikiran dan saling mengedukasi. Selain jiwa wirausaha, jiwa untuk meningkatkan ekonomi kreatif dan sociopreneur sangat terasa di kedai ini. Hal tersebut bisa dibuktikan dimana kudapan diambil dari konsumen yang berjualan kudapan, yang diajak untuk bekerjasama dengan menaruh dagangannya di kedai ini.

Berdasarkan uraian di atas maka dapat digambarkan bahwa Pak Putu Gde Ary Wicahyana menampilkan sosok wirausaha yang sukses dimana dalam ceritanya, Beliau mempunyai mimpi bahwa kopi lokal harus lebih dicintai daripada kopi luar negeri. Mimpi yang realistis dan tinggi ini mampu Ia ubah menjadi cita-cita yang harus dicapai dalam beberapa tahun kedepan. Pak Ary dengan kekuatan emosionalnya yang tinggi pada kopi cap Kupu-kupu Bola Dunia dan keyakinannya yang kuat berusaha sehingga mimpi itu bisa terwujud (power of dream). Sifat lain yang juga terlihat adalah karakter dasar dengan kekuatan emosional yang saling mendukung untuk sukses yaitu: determinasi (bisa menentukan mana yang baik dan tidak untuk usahanya), persistence (teguh dengan pendiriannya), keberanian untuk melakukan perubahan, struggle (berjuang di tengah banyaknya usaha kedai kopi lain), dan risk manager (mampu mengelola resiko atas apa yang sedang dikerjakan). Wirausaha pun menjadi tantangan baru dari Pak Ary yang berangkat dari seorang komikus.

Ia menyukai tantangan dan tidak pernah puas dengan apa yang didapat (high achiever). Di sela-sela kesibukannya mengelola kedai Bhineka Muda, Beliau juga sering diminta untuk menjadi pembicara untuk acara kewirausahaan di kampus baik di Bali maupun Jakarta, hal ini menunjukkan ambisi dan motivasi yang kuat (motivator) terutama untuk membangkitkan jiwa wirausaha mahasiswa. Pria berusia 41 tahun memiliki keyakinan yang kuat akan kemampuannya bahwa "dia bisa" (power of mind) serta seorang visioner dan mempunyai daya kreativitas yang tinggi. Hal ini bisa terlihat dari konsep interior di kedai yang setiap elemennya memiliki daya artistik yang tinggi dengan makna yang mendalam. Semangat beliau juga memperlihatkan sosok seorang yang mampu mengendalikan resiko yang ada (risk manager not just risk taker) yang terlihat tetap santai di tengah gempuran kedai kopi lokal yang menjamur. Jika melihat kesehariannya di kedai maka terlihat bahwa Ia memiliki kekuatan emosional (strong emotional attachment) baik dengan karyawan dan terutama dengan pelanggannya.

Selama peneliti melakukan observasi, terlihat juga bahwa sebagai seorang pemimpin haruslah bisa menjadi seorang problem solver untuk masalah-masalah yang sifatnya sehari-hari hingga yang strategis. Sebetulnya, beliau diuntungkan dengan kualitas kopi cap Kupu-kupu Bola Dunia yang sudah ada sejak tahun 1935 ini. Kreatifitas dalam pengolahan kopi dengan varian yang kekinian jelas memudahkan Ia untuk menjual dan memasarkan produknya (seller). Beliau juga bisa merangkul pengusaha muda lain, 
dengan produk kue atau camilan, untuk menjajakan jualannya di kedai Bhineka Muda. Sehingga pelanggan tidak hanya membeli kopi tetapi juga membeli makanan pendamping untuk "teman" menikmati kopi dan berbincang-bincang. Promosi digital dimanfaatkan secara maksimal, varian minum baru dibagikan melalui instastory sehingga siapapun yang melihat, pasti segera ingin mencobanya. Penampilannya yang nyentrik khas seniman sekilas terkesan orang yang sulit diatur, padahal Beliau adalah seorang creator ulung yang bisa menciptakan suatu perubahan, dari yang sudah mulai ditinggalkan menjadi sesuatu yang menarik hati.

Suatu hal yang baik, patut untuk ditiru. Satu hal lagi yang dapat diambil dari Pak Ary dimana konsep wirausahawan sosial (social entrepreneurs) sudah ada dalam konsep awal usahanya. Wirausahawan sosial menurut Zimmerer dan Scarborough (2008) adalah wirausahawan yang menggunakan berbagai keahlian mereka tidak hanya untuk membuat bisnis menjadi menguntungkan, tetapi juga untuk mencapai tujuan sosial dan lingkungan bagi kebaikan bersama. Pak Ary dengan keahliannya melihat peluang, memaksimalkan kualitas kopi cap Kupu-kupu Bola Dunia untuk mememperoleh keuntungan. Namun tidak hanya itu, dengan memperkerjakan karyawan yang masih muda namun terampil dalam mengolah kopi serta mengajak pelanggan yang mempunyai usaha kue/camilan untuk bergabung menjadi bukti nyata bahwa tujuannya tidak hanya profit namun juga tujuan kesejahteraan sosial. Demi kepedulian lingkungan hidup, Bhineka Muda tidak lagi menggunakan sedotan plastik sebagai bagian dari penerapan pengurangan sampah plastic di Bali.

Pembahasan terakhir akan terkait pemasaran, dimana menjamurnya kedai kopi lokal membuat seorang wirausaha semakin "panas" untuk bersaing. Pemahaman akan kebutuhan dan keinginan, menjaga hubungan baik dengan pelanggan, mempelajari perilaku konsumen, hingga perilaku digital pelanggan menjadi kunci dalam menghadapi persaingan. Untuk pemasaran, saat ini pemasaran yang tepat adalah dengan pemasaran hubungan (relationship marketing) atau manajemen hubungan pelanggan (customer relationship management/ CRM) yang merupakan suatu proses pengembangan, pemeliharaan, dan pengelolaan hubungan jangka panjang dengan pelanggan sehingga mereka tetap kembali berbelanja (Zimmerer dan Scarborough, 2008). Teori tersebut diterapkan betul oleh Pak Ary. Pada setiap kesempatan, dari kedai buka hingga tutup, Beliau akan menyapa semua pelanggan yang datang.

Mengontrol kualitas produk dilanjutkan dengan berbincang dengan pelanggan menjadi salah satu cara pemeliharaan agar pelanggan datang kembali. Media sosial, terutama Instagram, menjadi alat untuk mengelola hubungan jangka panjang. Informasi yang update terkait produk baru atau situasi kedai menjadikan pelanggan untuk selalu ingin datang menikmati kopi di Bhineka Muda dan juga Bhineka Djaja.

\section{KESIMPULAN}

Simpulan yang diperoleh dari penelitian ini adalah:

- Untuk memulai suatu usaha, ada baiknya melihat pada budaya atau tradisi lokal daerahnya sehingga dapat menjadi bagian dari ekonomi kreatif

- Menjadi wirausaha yang sukses harus lengkap memiliki ciri-ciri utama, mulai dari kekuatan akan mimpi (power of dreams) hingga menjadi sosok creator yang ulung.

- Berwirausaha tidak hanya fokus pada keuntungan namun juga memikirkan lingkungan sosial layaknya seorang wirausahawan sosial (social entrepreneur) dimana hasil usahanya bisa dirasakan langsung oleh para pemangku kepentingan. 
- Seorang wirausaha sukses juga harus bisa menjalin hubungan baik dengan pelanggannya. Pelajari perilakunya serta maksimalkan pemasaran digital sebagai "pengikat" dengan pelanggan. Jika keadaan ini berjalan secara terus menerus, maka bukanlah hal yang tidak mungkin bahwa masyarakat akan kembali mencintai kopi lokal daerahnya dibandingkan kopi dengan merek Internasional.

- Kelebihan penelitian ini adalah jiwa wirausaha Pak Ary dapat "ditularkan" kepada wirausaha muda lainnya untuk menggali tradisi daerahnya hingga dapat berusaha sembari melestarikan budaya lokal.

- Kekurangannya adalah karena jarak dan waktu maka wawancara tidak bisa lebih mendetail lagi

- Penelitian selanjutnya aka terkait dengan merek atau branding dimana akan diteliti lebih lanjut kekuatan elemen merek Kupu-kupu Bola Dunia yang sudah ada sejak tahun 1935.

\section{UCAPAN TERIMA KASIH}

Terimakasih yang sebesar-besarnya untuk Bapak Putu Gde Ary Wichyana atas waktu dan tempat yang diberikan sehingga terwujudnya artikel ini. Terimakasih juga dihaturkan untuk Panitia Seminar Nasional Dies Natalis Univeritas Sahid ke-31 atas kesempatannya serta LPPM Universitas Sahid untuk ruang publikasinya dalam Jurnal Kewirausahaan.

\section{DAFTAR PUSTAKA}

Dash, M., \& Kaur, K. (2012). Youth entrepreneurship as a way of boosting Indian economic competitiveness: A study of Orissa. International Review of Management and Marketing, 2(1), 10-21.

El Hasanah, L. L. N. (2015). Pengembangan Wirausaha Muda Ekonomi Kreatif Berbasis Budaya di Daerah Istimewa Yogyakarta. Jurnal Studi Pemuda, 4(2), 268-280.

Hendro, Ir. 2011. Dasar-dasar Kewirausahaan. Jakarta (ID): Penerbit Erlangga.

Putera, Andri Donnal. (2018). Produksi Kopi Indonesia Belum Maksmimal. [online] Tersedia di https://ekonomi.kompas.com/read/2018/08/08/125051626/produksikopi-indonesia-belum-maksimal [ diakses tanggal 7 April 2018]

Suyatna, H., \& Nurhasanah, Y. (2017). Sociopreneurship Sebagai Tren Karir Anak Muda. Jurnal Studi Pemuda, 6(1), 527-537.

Zimmerer, T. W., \& Scarboroug, N. M. (2005). Essentials of entrepreneurship and small business management. Prentice-Hall. 